\title{
Working
}

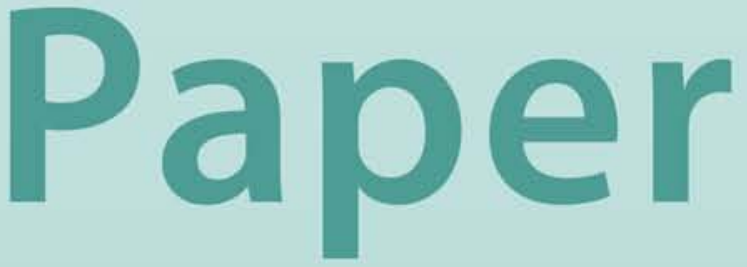


Why Is Micro Evidence on the Effects of

Uncertainty Not Replicated

In Macro Data?

Stephen Bond and Domenico Lombardi 


\title{
IMF Working Paper
}

Office of the Executive Director for Italy

\section{Why Is Micro Evidence on the Effects of Uncertainty Not Replicated In Macro Data?}

\author{
Prepared by Stephen Bond and Domenico Lombardi ${ }^{1}$ \\ Authorized for distribution by Pier Carlo Padoan
}

August 2005

\begin{abstract}
This Working Paper should not be reported as representing the views of the IMF. The views expressed in this Working Paper are those of the author(s) and do not necessarily represent those of the IMF or IMF policy. Working Papers describe research in progress by the author(s) and are published to elicit comments and to further debate.

This study investigates the relationship between uncertainty and investment using U.K. data at different levels of aggregation. Motivated by a comparative econometric analysis using a firm-level panel and aggregate time-series data, we analyze the implications of aggregating nonlinear microeconomic processes. Replicating firm-level evidence that uncertainty influences investment dynamics proves to be challenging. Even using perfectly consistent data sources, this requires both exact aggregation of the underlying micro equations, and controlling for the unobserved influences on investment that are commonly subsumed into time dummies in panel studies. These conditions are unlikely to be satisfied in most aggregate econometric studies.
\end{abstract}

JEL Classification Numbers: C20, D8, D92, E22

Keywords: Aggregation, Investment, Uncertainty

Author(s) E-Mail Address: steve.bond@nuf.ox.ac.uk; dlombardi@imf.org

\footnotetext{
${ }^{1}$ We are grateful, but do not wish to implicate, N. Bloom, S. Brooks, R. Flood, C. Kelly, M. Soderbom, M.F. Viola, and I. Visco, for helpful comments. N. Bate and S. Siciarz provided excellent research and editorial assistance, respectively. This paper was started when D. Lombardi was visiting Her Majesty's Treasury in London. The authors gratefully acknowledge financial support from H.M. Treasury; the Economic and Social Research Council Centre for Fiscal Policy at the Institute for Fiscal Studies, London; and Oxford University.
} 


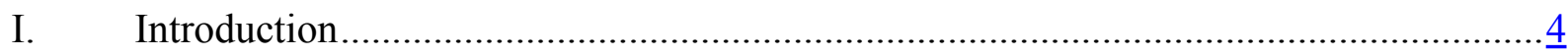

II. Firm-Level Investment Dynamics …………..................................................

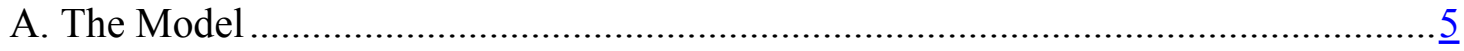

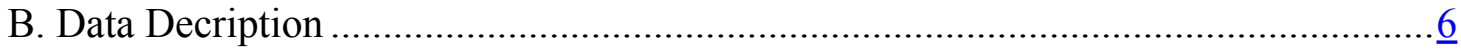

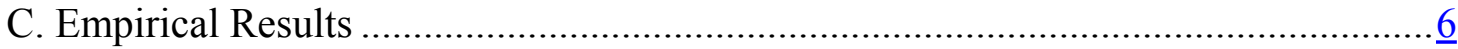

III. Aggregate Investment Dynamics ......................................................................

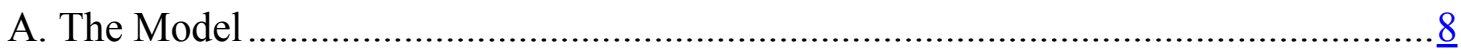

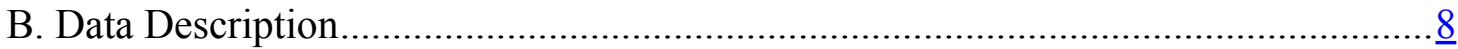

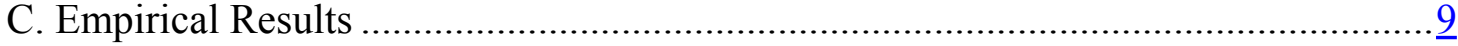

IV. Aggregation Issues: A First Exploration...............................................................

V. Aggregation Issues: Common Time-Varying Shocks ................................................12

A. Estimating the Common Time-Varying Shocks ……………………....................13

VI. Empirical Analysis Under Observed Aggregation ………………...........................

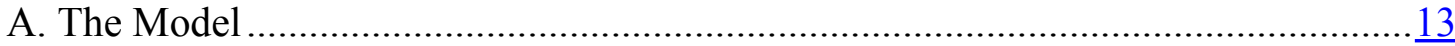

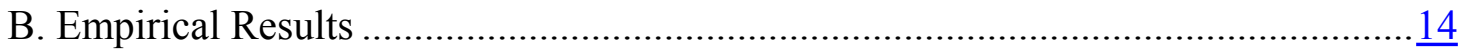

VII. Empirical Analysis Under Exact Aggregation..........................................................

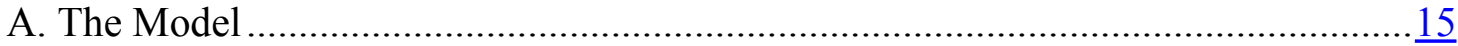

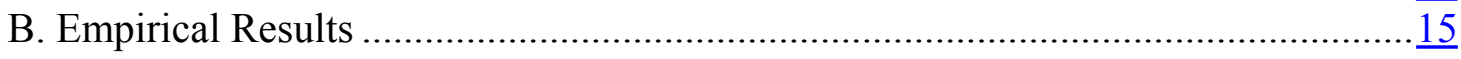

VIII. Results from a Monte Carlo Analysis...................................................................

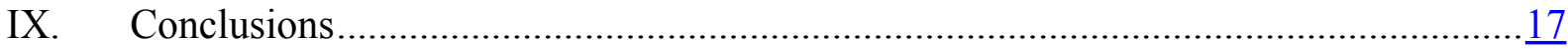

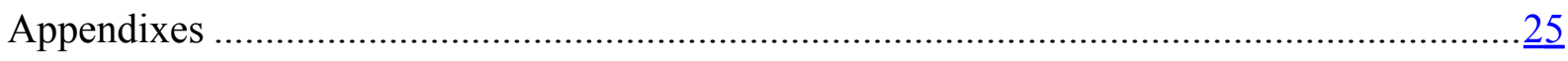

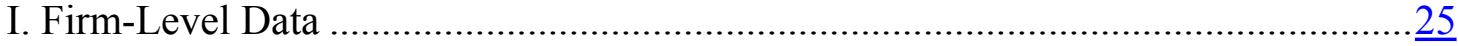

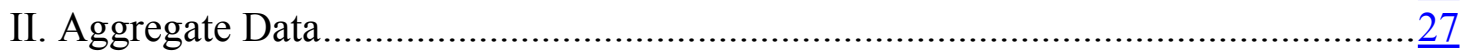

III. The Aggregate Error Correction Term ……………………………………....

IV. The Monte Carlo Experiment ............................................................................29 
Tables

1. Descriptive Statistics - Firm Panel ................................................................... $\frac{19}{19}$

2. Descriptive Statistics - Manufacturing Sector................................................. $\frac{19}{20}$

3. Firm-Level Investment Equation ...........................................................

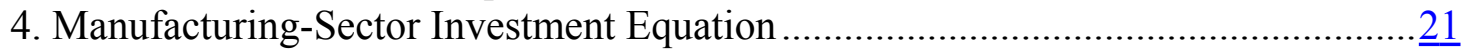

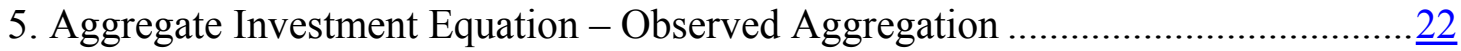

6. Aggregate Investment Equation - Exact Aggregation...................................

Figures

1. Common Time-Varying Shocks ........................................................... 24

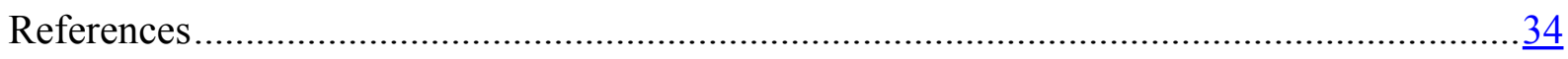




\section{INTRODUCTION}

Recent theoretical contributions have emphasized the effects of uncertainty and irreversibility on short-run investment dynamics (Abel and Eberly, 1999; and Bloom, 2000). A number of microeconometric studies have found evidence consistent with the predicted slower response of investment to demand shocks for firms facing higher levels of uncertainty (see, for example, Guiso and Parigi, 1999; Bloom, Bond, and Van Reenen, 2003; and Bond and Lombardi, 2004).

This study is motivated by our inability to detect similar evidence using aggregate time-series data for the U.K. manufacturing sector. Does this imply that uncertainty has no effect on aggregate investment dynamics? Our results indicate that this is not necessarily the case. Even if the firm-level and aggregate data sources are consistent, a combination of misspecification and omitted variables can generate misleading inference from the aggregate investment model.

Earlier studies of business investment behavior by Huizinga (1993) and Goldberg (1993) have noted inconsistencies between results obtained at different levels of aggregation, although they have not attempted to investigate the sources that may account for them. Our analysis highlights two important factors. Microeconometric specifications tend to be nonlinear in significant respects, so that the available aggregate series are not related in the same way as their microeconomic counterparts. Panel data specifications also commonly control for unobserved influences such as the user cost of capital and demand or technology conditions by including dummy variables for each year of the sample. The inclusion of simple trends in aggregate specifications may not control nearly so well for these omitted factors. We show that an aggregate econometric specification can replicate the evidence found using firm-level data, but only if: (i) the aggregate and firm-level data are obtained from consistent sources; (ii) the aggregate variables are constructed from the firm-level variables using exact aggregation; and (iii) the aggregate specification controls for the unobserved influences that are captured by time dummies in the panel model. Since these conditions are unlikely to be met in typical aggregate econometric studies, evidence about the effects of uncertainty on aggregate investment dynamics obtained from such analyses is potentially misleading.

The paper is organized as follows. We first report a comparative econometric analysis of investment behavior using a micro panel of U.K. manufacturing firms (Section II) and aggregate time-series data for the U.K. manufacturing sector (Section III). Subsequently, we analyze the theoretical implications of aggregating nonlinear micro investment processes (Section IV) and generalize this analysis to allow for common, unobserved influences on the firms' investment decisions (Section V). We then construct aggregate series from our firm-level data, including estimates of the common, unobserved factor obtained from the intercepts of our microeconometric specification. We show that consistent evidence about the impact of uncertainty on investment dynamics can be obtained by using an exact aggregate counterpart of the microeconomic model, and including this additional series to control for evolving, unobserved influences. However, results from aggregate specifications that do not meet all these conditions are shown to be misleading (Sections VII and VIII). A small Monte Carlo experiment yields similar findings to those obtained with the U.K. investment data (Section VIII). Section IX concludes. 


\section{FIRM-LEVEL INVESTMENT DYNAMICS}

\section{A. The Model}

We follow Bloom, Bond, and Van Reenen (2003) in considering a simple dynamic model of firm-level investment, which allows the impact effect of demand growth to vary with the level of uncertainty. The specific model we estimate is an augmented error correction model (ECM) specification of the form:

$$
\begin{aligned}
\left(\frac{I_{i t}}{K_{i, t-1}}\right)= & \alpha_{t}+\omega_{0} \Delta y_{i t}+\omega_{1} \Delta y_{i, t-1} \\
& +\omega_{2}\left(\sigma_{i t} \Delta y_{i t}\right)+\theta(k-y)_{i, t-2} \\
& +\psi\left(\frac{C_{i, t-1}}{K_{i, t-2}}\right)+\eta_{i}+\varepsilon_{i t} .
\end{aligned}
$$

Here $I_{i t}$ is gross investment by firm $i$ in year $t, K_{i, t-1}$ is the net capital stock at the end of the previous year, $y_{i t}$ is the $\log$ of real sales, $k_{i t}$ is the $\log$ of the capital stock, $C_{i, t-1}$ is cash flow in year $t-1$, and $\sigma_{i t}$ is a measure of uncertainty.

In the long run, this specification relates the firm's capital stock log-linearly to real sales and to unobserved components that may reflect, for example, the cost of capital or demand and technology conditions. These factors are controlled for by the inclusion of year-specific intercepts $\left(\alpha_{t}\right)$ and firm-level "fixed" effects $\left(\eta_{i}\right)$ in our microeconometric investment model. In the short run, investment rates may depend on recent sales growth and profitability, while a negative parameter $\theta$ on the "error correction term" ensures that capital adjusts eventually toward the long-run target.

As shown by Bloom, Bond, and Van Reenen (2003), a key prediction from the analysis of investment under (partial) irreversibility is that the short-run effect of demand shocks on firm-level investment will tend to be smaller for firms facing a higher level of uncertainty. In this specification the interaction term between sales growth and measured uncertainty allows for such heterogeneity in the impact effect of demand shocks, and finding $\omega_{2}<0$ would be consistent with the predicted more cautious response of investment to new information about demand for firms subject to higher uncertainty. ${ }^{2}$

\footnotetext{
${ }^{2}$ As emphasized by, for example, Abel and Eberly (1999), this theoretical approach is consistent with a positive, negative, or zero effect of higher uncertainty on the average level of the capital stock in the long run. We also considered an additional linear term in the level of measured uncertainty in equation (1), that would allow for a long-run effect on capital stock levels, but found this to be insignificant. See Bloom, Bond, and Van Reenen (2003) for further discussion.
} 


\section{B. Data Description}

The firm-level dataset is obtained from the Datastream on-line service which covers all companies quoted on the U.K. stock market. Our sample is a subset of that used by Bloom, Bond, and Van Reenen (2003). For this investigation we select firms operating principally in the manufacturing sector for which data is available for a relatively long period, a minimum of 22 years between 1972 and 1997. This choice is the result of a trade-off between two conflicting concerns. On the one hand, a completely balanced sample would make the aggregate analysis simpler. However, such a choice would be very costly in terms of lost observations, since we would end up working either with a much smaller number of firms or with a much shorter time period. ${ }^{3}$ On the other hand, the aim of maximizing the total number of firm-year observations available would result in a heavily unbalanced panel, further complicating the aggregate analysis in the second part of this study. Our choice to focus on a slightly unbalanced panel of 205 firms remaining in the sample for at least 22 years provides a large number of observations (almost 5,000) covering a long time period (26 years), which allows us to investigate investment behavior from both a panel data and a time-series perspective.

We report in Table 1 some basic descriptive statistics for this panel (text tables are grouped following Section IX). As can be seen, the sample consists mainly of large firms, whose total annual investment expenditure is typically the outcome of many underlying investment decisions for multiple types of capital, production lines, plants, and subsidiaries. Importantly, the model developed by Bloom, Bond, and Van Reenen (2003) is robust to these aggregation issues, and indicates that (partial) irreversibility at the level of the underlying investment decisions can have important implications for firm-level investment dynamics, even though zero investment is almost never observed in annual data on large U.K. firms.

Our firm-level measure of uncertainty $\left(\sigma_{i t}\right)$ is the annual standard deviation of a firm's daily share returns, along the lines of previous studies such as Leahy and Whited (1996) and Bloom, Bond, and Van Reenen (2003). ${ }^{4}$ This provides a time-varying measure of uncertainty that reflects many aspects of the firm's environment, and has been found to be informative about investment behavior in those earlier studies.

\section{Empirical Results}

The estimation of equation (1) on this dataset requires methods for dynamic panel data models. Blundell and Bond (1998) have developed a generalized methods of moments (GMM) system estimator that, while controlling for the presence of unobserved firm-specific effects, can significantly improve on the efficiency of the basic Arellano and Bond (1991) first-differenced estimator.

\footnotetext{
${ }^{3}$ See Table A.1.1 in Appendix I.

${ }^{4}$ Appendix I provides more details of this, and the other firm variables that we use.
} 
The validity of the instruments used is assessed by means of a Sargan test of overidentifying restrictions. Our preferred results here treat sales, cash flow, and measured uncertainty as predetermined variables, in order to ensure consistency with the aggregate analysis performed in the second part of the paper. However, while the particular results reported in this section are used as the benchmark for the subsequent aggregate analysis, the main findings were found to be robust to different choices of the instrument set or to alternative specifications of the dynamic econometric model. ${ }^{5}$

Table 3 reports one-step GMM estimates. ${ }^{6}$ Overall the diagnostic tests appear satisfactory, with no evidence of second-order serial correlation in the first-differenced residuals, ${ }^{7}$ and no rejection of the overidentifying restrictions at standard significance levels. Despite differences in the samples and econometric specifications, our basic results are very similar to those reported by Bloom, Bond, and Van Reenen (2003). Firm-level investment dynamics are well described by an error correction model in which investment responds to sales growth and cash flow in the short run, ${ }^{8}$ and adjusts toward a target for the capital stock that is proportional to real sales in the long run.

We stress two features of these results that are important for our analysis. First, we reject the null hypothesis that the response of investment to sales growth is common to all firms, finding a significantly weaker impact effect for firms subject to higher uncertainty. As predicted by models of (partial) irreversibility, uncertainty plays an important role in shaping investment dynamics. Second, we find that year dummies are highly significant explanatory variables. In common with many microeconometric specifications, this model of firm-level investment is therefore controlling for the effects of a range of unspecified macroeconomic factors, including, for example, interest rates, inflation, taxes, technical progress, and business cycle influences.

\footnotetext{
${ }^{5}$ In particular, our analysis here omits for simplicity additional terms that allow for a non-linear response of investment to demand shocks. In line with the results of Bloom, Bond and Van Reenen (2003), we found significant evidence of a convex response when such terms were added to our microeconometric model.

${ }^{6}$ Very similar results were found using an (asymptotically) efficient two-step GMM estimator, with standard errors corrected for the presence of estimated parameters in the weight matrix, following Windmeijer (2000).

${ }^{7}$ This is consistent with the residual error component $\left(\varepsilon_{i t}\right)$ in equation (1) being serially uncorrelated, which is required for the validity of our instrument set.

${ }^{8}$ Our interpretation assumes that rates of profitability, like our cash flow variable, are mean-reverting around a firm-specific constant, related to the firm's long-run equilibrium rate of return. In this case these results do not identify whether cash flow also has a long-run effect on the capital stock, since the long-run mean of the cash flow variable is absorbed by the firm-specific effects.
} 


\section{Aggregate Investment Dynamics}

\section{A. The Model}

In this section, we estimate a simple aggregate counterpart to equation (1), using annual time-series data available for the entire U.K. manufacturing sector. The model estimated is:

$$
\begin{aligned}
\left(\frac{I_{t}}{K_{t-1}}\right)^{O N S}= & c+t+\omega_{0} \Delta y_{t}^{O N S}+\omega_{1} \Delta y_{t-1}^{O N S} \\
& +\omega_{3}\left(\sigma_{t}^{O N S} \Delta y_{t}^{O N S}\right)+\theta(k-y)_{t-2}^{O N S} \\
& +\psi_{1} F I N_{t-1}^{O N S}+\varepsilon_{t},
\end{aligned}
$$

where the superscript $O N S$ indicates that the data come from aggregate sources described in the next section. In this case investment $\left(I_{t}\right)$ is measured net of (assumed) depreciation and retirements. $F I N_{t-1}$ denotes the percentage of firms reporting that their investment spending is limited by the availability of finance in response to surveys conducted in year $t-1$. We include this as a proxy for financial conditions, given that no aggregate cash flow data are available for the manufacturing sector as a whole. More importantly, our aggregate investment model controls for unobserved macroeconomic factors only to the extent that these are proxied by an intercept $(c)$ and a linear trend $(t)$.

\section{B. Data Description}

Data on investment, capital stock, and output used in this aggregate specification are obtained from the U.K. Office of National Statistics (ONS) and cover the whole manufacturing sector. ${ }^{9}$ These annual data cover the same period, 1972-1997, as our firm panel. Table 2 reports some basic descriptive statistics. The mean net investment rate is less than 1 percent, indicating very low growth of the U.K. manufacturing capital stock over this period. The average annual growth rate of real manufacturing value added is also below 1 percent. Other sectors of the U.K. economy enjoyed stronger investment and faster output growth over the same period. ${ }^{10}$

Our measure of uncertainty here is the annual standard deviation of daily returns on the FTSE Index for the U.K. nonfinancial sector. This includes, but is not limited to, quoted firms in the manufacturing sector. As noted above, our liquidity variable here is a survey measure that was also used by Bean (1981) in his econometric analysis of U.K. manufacturing investment, and is described in Appendix II.

\footnotetext{
${ }^{9}$ Appendix II provides more details of the aggregate data used in this section.

${ }^{10}$ See, for example, Bank of England (2002) for an analysis of recent trends in U.K. aggregate fixed investment, and Koeva (2003) for a comparative appraisal of U.K. investment performance relative to other OECD economies.
} 
The aggregate data sources available at the manufacturing level differ in potentially important ways, with respect to both concepts and coverage, from those used in our firm-level model. For example, here we use real value added rather than real sales, and net investment rather than gross investment. Our firm-level investment data cover worldwide investment undertaken by manufacturing firms quoted on the London Stock Exchange, including investment by their foreign subsidiaries outside the U.K.; while the ONS aggregate data covers all manufacturing investment in the U.K., including that undertaken by unquoted companies and by U.K. subsidiaries of foreign firms. We will explore the importance of these data differences in Section VI below. For the moment, we also ignore differences in the econometric methods used in our panel data and time-series analyses.

\section{Empirical Results}

Table 4 reports ordinary least squares (OLS) estimates of equation (2). ${ }^{11}$ Here the diagnostic tests indicate serious problems, indicating the presence of autocorrelation in the residuals as well as rejection of the functional form we have imposed. These results point to important misspecifications of the model estimated at the aggregate level.

Furthermore, while there is again evidence that investment responds to output growth and liquidity, and adjusts in the direction of a long-run target for the capital stock, in this case we find no evidence that the impact effect of output growth varies with the level of uncertainty. The coefficient on the interaction term between sectoral uncertainty and output growth has the opposite sign to that found in our firm-level model, and is insignificantly different from zero. The same result was found in aggregate specifications that considered different timings (for example, $\sigma_{t-1}^{O N S} \Delta y_{t}^{O N S}$ and $\sigma_{t-1}^{O N S} \Delta y_{t-1}^{O N S}$ ), and in specifications that added the lagged level of measured uncertainty $\left(\sigma_{t-1}^{O N S}\right)$ to equation $(2){ }^{12}$

Based on this preliminary evidence, the investment model that was successfully estimated on micro data appears to be soundly rejected at this more aggregated level. For this or other reasons, the evidence that uncertainty shapes firm-level investment dynamics is not reproduced in our specification for the manufacturing sector. These differences may reflect several factors, including data and estimation differences, and biases due to aggregation. In the rest of this paper we investigate the sources that may have generated this apparently inconsistent empirical evidence.

\footnotetext{
${ }^{11}$ The use of OLS here is consistent with the assumption that output, uncertainty, and liquidity are predetermined variables, as we assumed for their firm-level counterparts in the previous section. We also considered instrumental variables (IV) estimation to control for the possible endogeneity of some of these regressors. The IV estimates were not substantively different from the OLS results presented here.

${ }^{12}$ The linear uncertainty term was also found to be insignificant.
} 


\section{Aggregation Issues: A First Exploration}

In this section we present a simple analysis of the aggregation of this kind of investment equation from the micro units up to a higher level. We distinguish between exact aggregation - the relationship between aggregate series that follows from explicitly aggregating the micro investment processes - and "observed" aggregation — the relationship obtained simply by replacing the firm-level variables in an equation like (1) with available aggregate counterparts, as we did to obtain the model estimated in Section III.

We first assume that a firm's capital stock follows the simple process described by:

$$
\ln K_{i t}=\alpha_{1} \ln K_{i, t-1}+\beta_{0} \ln Y_{i t}+\beta_{1} \ln Y_{i, t-1}+\epsilon_{i t},
$$

where $K_{i t}$ is the net capital stock at the end of period $t$, and $Y_{i t}$ is the level of output in period $t$. Assuming that the long-run elasticity $\left(\beta_{0}+\beta_{1}\right) /\left(1-\alpha_{1}\right)=1$ and using the approximation $\Delta \ln K_{i t} \approx I_{i t} / K_{i, t-1}-\delta$, we can reparameterize this relationship as:

$$
I_{i t} / K_{i, t-1}=\beta_{0} \Delta \ln Y_{i t}+\left(\alpha_{1}-1\right)\left(\ln K_{i, t-1}-\ln Y_{i, t-1}\right)+\epsilon_{i t} .
$$

In this section, since we focus on aggregation only, we consider a common depreciation rate subsumed in a constant term that is omitted here for simplicity.

Under exact aggregation, considering a population of $i=1,2, \ldots, N$ firms, summing equation (4) over the $N$ firms gives:

$$
\begin{aligned}
\sum_{i=1}^{N} I_{i t} / K_{i, t-1}= & \beta_{0} \sum_{i=1}^{N} \Delta \ln Y_{i t}+\left(\alpha_{1}-1\right)\left(\sum_{i=1}^{N}\left(\ln K_{i, t-1}-\ln Y_{i, t-1}\right)\right) \\
& +\sum_{i=1}^{N} \epsilon_{i t} .
\end{aligned}
$$

However, when working with aggregate data, we do not observe series like $\sum_{i=1}^{N} I_{i t} / K_{i, t-1}$, $\sum_{i=1}^{N} \Delta \ln Y_{i t}$ or $\left(\sum_{i=1}^{N}\left(\ln K_{i, t-1}-\ln Y_{i, t-1}\right)\right)$. Instead we observe aggregate investment rates of the form $\frac{\sum_{i=1}^{N} I_{i t}}{\sum_{i=1}^{N} K_{i, t-1}}$, aggregate output growth like $\ln \left(\sum_{i=1}^{N} Y_{i t}\right)-\ln \left(\sum_{i=1}^{N} Y_{i, t-1}\right)$, and an aggregate error correction term defined as $\left(\ln \left(\sum_{i=1}^{N} K_{i, t-1}\right)-\ln \left(\sum_{i=1}^{N} Y_{i, t-1}\right)\right)$.

If we ignore these differences and attempt to estimate the same specification using the observed aggregate data, the model we estimate is instead: 


$$
\begin{aligned}
\frac{\sum_{i=1}^{N} I_{i t}}{\sum_{i=1}^{N} K_{i, t-1}}= & b_{0}\left(\ln \left(\sum_{i=1}^{N} Y_{i t}\right)-\ln \left(\sum_{i=1}^{N} Y_{i, t-1}\right)\right) \\
& +\left(a_{1}-1\right)\left(\ln \left(\sum_{i=1}^{N} K_{i, t-1}\right)-\ln \left(\sum_{i=1}^{N} Y_{i, t-1}\right)\right)+u_{t} .
\end{aligned}
$$

However, equation (5) does not imply equation (6). In general, $\sum_{i=1}^{N}\left(I_{i t} / K_{i, t-1}\right) \neq \frac{\sum_{i=1}^{N} I_{i t}}{\sum_{i=1}^{N} K_{i, t-1}}$, $\sum_{i=1}^{N} \Delta \ln Y_{i t} \neq \ln \left(\sum_{i=1}^{N} Y_{i t}\right)-\ln \left(\sum_{i=1}^{N} Y_{i, t-1}\right)$ and $\sum_{i=1}^{N}\left(\ln K_{i, t-1}-\ln Y_{i, t-1}\right) \neq$ $\left(\ln \left(\sum_{i=1}^{N} K_{i, t-1}\right)-\ln \left(\sum_{i=1}^{N} Y_{i, t-1}\right)\right)$.

A useful way of considering equation (5) is to divide both sides by $N$, and to express all terms as simple averages of the underlying firm-level variables:

$$
\begin{aligned}
\frac{1}{N} \sum_{i=1}^{N} I_{i t} / K_{i, t-1}= & \beta_{0} \frac{1}{N} \sum_{i=1}^{N} \Delta \ln Y_{i t} \\
& +\left(\alpha_{1}-1\right) \frac{1}{N}\left(\sum_{i=1}^{N}\left(\ln K_{i, t-1}-\ln Y_{i, t-1}\right)\right)+\frac{1}{N} \sum_{i=1}^{N} \epsilon_{i t} .
\end{aligned}
$$

Equation (7) shows that under exact aggregation, the unweighted average of the investment rates for a population of $N$ firms can be related to the unweighted average of each of the explanatory variables appearing in equation (4).

Equation (6) can also be approximated in the following manner:

$$
\begin{aligned}
\sum_{i=1}^{N} w_{k, i, t}\left(I_{i t} / K_{i, t-1}\right)= & b_{0} \sum_{i=1}^{N} w_{y, i, t} \Delta \ln Y_{i t} \\
& +\left(a_{1}-1\right) \sum_{i=1}^{N} w_{y, i, t}\left(\ln \left(K_{i, t-1}\right)-\ln \left(Y_{i, t-1}\right)\right)+u_{t} .
\end{aligned}
$$

where $w_{k, i, t}=\frac{K_{i, t-1}}{\sum_{j=1}^{N} K_{j, t-1}}$ and $w_{y, i, t}=\frac{Y_{i, t-1}}{\sum_{j=1}^{N} Y_{j, t-1}}$. Writing the growth rates of the aggregate capital stock and output series appearing in equation (6) as weighted averages of the underlying micro growth rates is quite standard. The derivation of the aggregate error correction term in equation (6) as the weighted average of the underlying firm-level error correction terms is detailed in Appendix III. 
Equation (8) shows that estimating the same model using the observed aggregate data corresponds to using weighted averages of the firm-level variables in place of the unweighted averages that appear in the exactly aggregated specification. Only under restrictive conditions for which the weighted averages in equation (8) behave exactly like the unweighted averages in equation (7) will the model based on observed aggregate data identify the same parameters as those that appear in the firm-level investment process equation (4).

\section{Aggregation Issues: Common Time-VArying Shocks}

Investment equations estimated at the micro level generally allow for the presence of common time-varying influences on firm investment decisions, which are controlled for by the inclusion of year-specific intercepts. These time dummies control for common factors such as interest rates, tax rates, and business confidence. Our benchmark model estimated in Section II included time dummies and found these to be highly significant. In this section we extend our analysis of aggregation to consider the implications of common (unobserved) time-varying shocks for the aggregate investment equations.

To consider this, we now add time-varying intercepts $\left(\alpha_{t}\right)$ to the baseline specification given by equation (3) above:

$$
\ln K_{i t}=\alpha_{t}+\alpha_{1} \ln K_{i, t-1}+\beta_{0} \ln Y_{i t}+\beta_{1} \ln Y_{i, t-1}+\epsilon_{i t} .
$$

Following the same steps, we can rewrite the equation for the investment rate under exact aggregation (i.e. equation (7)) as:

$$
\begin{aligned}
\frac{1}{N} \sum_{i=1}^{N} I_{i t} / K_{i, t-1}= & \alpha_{t}+\beta_{0} \frac{1}{N} \sum_{i=1}^{N} \Delta \ln Y_{i t} \\
& +\left(\alpha_{1}-1\right) \frac{1}{N}\left(\sum_{i=1}^{N}\left(\ln K_{i, t-1}-\ln Y_{i, t-1}\right)\right)+\frac{1}{N} \sum_{i=1}^{N} \epsilon_{i t} .
\end{aligned}
$$

Equation (10) illustrates another possibly important source of bias when attempting to estimate an aggregate investment equation. To the extent that common time-varying shocks as proxied by $\alpha_{t}$ are present at the micro level but omitted in the aggregate investment specification, they will be part of the error term of the time-series model. Unless $\alpha_{t}$ happens to follow some simple process like a linear trend, it may generate a source of omitted variable bias in the estimation of equation (10). 


\section{A. Estimating the Common Time-Varying Shocks}

To illustrate this, we can obtain estimates of the common aggregate shocks $\left(\alpha_{t}\right)$ from the microeconometric investment equation presented in Section II. The GMM system estimator identifies the intercept for each period in which equation (1) is observed. ${ }^{13}$ Figure 1 plots these estimates of the common time-varying shocks that influence the investment rates of our sample of U.K. manufacturing firms. As can be seen, this series is countercyclical, with peaks occurring in 1975, 1980, and 1990 when the U.K. economy experienced recessions. Importantly, this series will not be well proxied by the inclusion of a simple linear trend in our aggregate specification. Since the key explanatory variables in our aggregate model (e.g., output growth, profitability, and measured uncertainty) also exhibit clear cyclical patterns, the omission of a good proxy for unobserved common influences is likely to generate important omitted variable biases in the results for aggregate specifications. We illustrate this further in the empirical analysis reported in the following Sections.

\section{Empirical Analysis Under Observed Aggregation}

\section{A. The Model}

In this Section, we consider the importance of different data sources in accounting for the different results obtained in our investment equations for manufacturing firms and for the manufacturing sector as a whole, presented in Sections II and III, respectively. We noted several inconsistencies in the definitions and coverage of the company accounts data and the ONS macro data. To eliminate these, we can use the firm-level data to construct aggregate counterparts to the basic variables included in our microeconometric investment model. This ensures both that the definitions of our constructed aggregate data are identical to the definitions used in our micro data, and that the constructed aggregate data refers to the same population of firms.

To implement this, the specification in equation (8) is particularly helpful. By expressing the relevant variables in terms of their weighted averages computed across the sample of firms observed for each period, this allows us to work with the unbalanced panel of firms considered in Section II. ${ }^{14}$ For example, the weighted average figure for real sales growth between periods $t-1$ and $t$ included in the specification below is constructed as a weighted average of the individual growth rates for all firms for which we have data in both periods $t-1$ and $t$.

\footnotetext{
${ }^{13}$ This is convenient but not essential. Writing the equation in levels as $y_{i t}=\alpha_{t}+x_{i t} \beta+\varepsilon_{i t}$, we could always recover consistent estimates of $\alpha_{t}$ as $y_{i t}-x_{i t} \widehat{\beta}$ using any consistent estimator $\widehat{\beta}$.

${ }^{14}$ See Appendix I for more details on the composition of this panel.
} 
Accordingly, the aggregate specification we estimate under observed aggregation is:

$$
\begin{aligned}
\left(I_{t} / K_{t-1}\right)^{O A}= & c+t+\omega_{0} \Delta y_{t}^{O A}+\omega_{1} \Delta y_{t-1}^{O A}+\theta(k-y)_{t-2}^{O A} \\
& +\psi\left(C_{t-1} / K_{t-2}\right)^{O A}+\omega_{2}\left(\sigma_{t}^{O A} * \Delta y_{t}^{O A}\right)+u_{t}
\end{aligned}
$$

where $c$ is a constant, $t$ is a linear trend, $\left(I_{t} / K_{t-1}\right)^{O A}=\sum_{i=1}^{N} w_{k, i, t}\left(I_{i t} / K_{i, t-1}\right)$, $\Delta y_{t}^{O A}=\sum_{i=1}^{N} w_{y, i, t} \Delta \ln Y_{i t},(k-y)_{t-2}^{O A}=\sum_{i=1}^{N}\left(w_{y, i, t-1}\left(\ln \left(K_{i, t-2}\right)-\ln \left(Y_{i, t-2}\right)\right)\right.$, $\left(C_{t-1} / K_{t-2}\right)^{O A}=\sum_{i=1}^{N} w_{k, i, t-1}\left(C_{i, t-1} / K_{i, t-2}\right)$, and $u_{t}$ is an error term. Equation (11) again allows the impact effect of demand growth to vary with the level of measured uncertainty. Our aggregate measure of uncertainty $\left(\sigma_{t}^{O A}\right)$ is constructed here as $\sigma_{t}^{O A}=\sum_{i=1}^{N}\left(\frac{m v_{i t}}{\sum_{j=1}^{N} m v_{j t}}\right) \sigma_{i t}$. This is a weighted average of the firm-specific uncertainty measures $\sigma_{i t}$, using market value weights, where $m v_{i t}$ is the market value of firm $i$ at time $t$.

\section{B. Empirical Results}

Column (1) of Table 5 reports OLS estimates of equation (11). Although the diagnostic tests do not reject this specification as strongly as was the case for our aggregate investment equation using the ONS data for the U.K. manufacturing sector (Table 4), important aspects of the estimated coefficients are still unsatisfactory. The only coefficient that is correctly signed and statistically significant is that on the cash flow term, while the coefficient on the error correction term is statistically significant but incorrectly signed. This specification suggests no short-run effect of real sales growth on investment, and perhaps not surprisingly in view of this, finds no evidence that this impact effect varies with the level of uncertainty.

Column (2) of Table 5 investigates the importance of omitted variable biases due to the exclusion of common unobserved influences on firm-level investment decisions from this aggregate specification. The simple linear trend is replaced here by the constructed series for $\alpha_{t}$ that was obtained from our microeconometric model and plotted in Figure 1. As expected, this explanatory variable is highly significant. The inclusion of this term also has an important effect on the remaining parameter estimates. The cash flow term becomes insignificant, while there is now significant evidence of an effect from lagged sales growth, and the error correction term is correctly signed and statistically significant. Importantly, however, we still detect no evidence of significant heterogeneity in the impact effect of sales growth on investment between periods with high and low levels of measured uncertainty.

To summarize, the aggregate investment equations using our constructed analogues of the observed aggregate series do not reproduce parameter estimates that are similar to those obtained using the firm-level panel data. This indicates that differences in the definitions and coverage of the variables are not primarily responsibe for the differences we found when comparing the results using firm-level and aggregate manufacturing datasets. There is some evidence that the 
exclusion of a good proxy for common unobserved shocks from the aggregate specifications has an important effect on the results, but even controlling for these factors, we are unable to find significant evidence that uncertainty affects short-run investment dynamics when we use the aggregate data in this way.

\section{Empirical Analysis Under EXact Aggregation}

\section{A. The Model}

In this Section, we estimate the relationship between the aggregate series that is implied by exact aggregation of the underlying microeconomic investment equations. To do this, we again make use of the aggregate relationship expressed in terms of averages rather than sums of the microeconomic variables. As shown in equation (7), exact aggregation gives a relationship between the unweighted averages of the firm-level variables. Note that the estimation of this relationship is possible here only because we have the underlying firm-level data to generate these unweighted averages of ratios and growth rates, and would not typically be feasible using published aggregate series.

The aggregate specification we consider under exact aggregation is thus:

$$
\begin{aligned}
\left(I_{t} / K_{t-1}\right)^{E A}= & c+t+\omega_{0} \Delta y_{t}^{E A}+\omega_{1} \Delta y_{t-1}^{E A}+\theta(k-y)_{t-2}^{E A} \\
& +\psi\left(C_{t-1} / K_{t-2}\right)^{E A}+\omega_{2}\left(\sigma_{t} * \Delta y_{t}\right)^{E A}+\varphi_{t},
\end{aligned}
$$

where $\left(I_{t} / K_{t-1}\right)^{E A}=\frac{1}{N} \sum_{i=1}^{N} I_{i t} / K_{i, t-1}, \Delta y_{t}^{E A}=\frac{1}{N} \sum_{i=1}^{N} \Delta \ln Y_{i t}, \quad(k-y)_{t-2}^{E A}=$

$\frac{1}{N}\left(\sum_{i=1}^{N}\left(\ln K_{i, t-2}-\ln Y_{i, t-2}\right)\right),\left(\sigma_{t} * \Delta y_{t}\right)^{E A}=\frac{1}{N} \sum_{i=1}^{N}\left(\sigma_{i t} * \Delta \ln Y_{i t}\right),\left(C_{t} / K_{t-1}\right)^{E A}=$ $\frac{1}{N} \sum_{i=1}^{N} C_{i, t-1} / K_{i, t-2}$ and $\varphi_{t}$ is an error term.

\section{B. Empirical Results}

Columns (1) and (2) of Table 6 report OLS estimates of equation (12), with and without the inclusion of the linear trend. While the linear trend term is significant, and its inclusion affects the results, neither of these specifications is satisfactory. In both cases, there is evidence of functional form misspecification, and the estimated parameters are very different from those obtained using the firm-level panel. For example, in column (2) the error correction term is statistically significant but incorrectly signed. In column (1), the impact effect of sales growth on investment is found to be increasing with the level of uncertainty, which is the opposite sign to the relationship found using the micro data. Simply using the variables implied by exact aggregation has not obviously improved the results found for these aggregate time-series models.

These findings change dramatically when we replace the simple linear trend term by our constructed series for $\alpha_{t}$. As reported in column (3) of Table 6, this explanatory variable is again highly significant, and has an estimated coefficient that is not significantly different from the 
expected value of unity. When we control for common, unobserved influences on investment in this way, the diagnostic tests indicate no serious problems with this exactly aggregated specification. Moreover, the estimated coefficients are very similar to those found using the firm-level panel (Table 3). The short-run effects of current and lagged sales growth are both significant, with coefficients ( 0.4308 and 0.1072 , respectively) very close to the corresponding estimates in the microeconometric specification ( 0.4291 and 0.1051 , respectively). The coefficient on the error correction term $(-0.1041)$ is correctly signed and highly significant, and very similar to that found in the panel data model $(-0.0963){ }^{15}$

We are particularly interested in the effect of uncertainty on the impact effect of sales growth on investment. The estimated coefficient on the interaction term between real sales growth and measured uncertainty is now found to be negative (-0.1249), statistically significant, and very close to the corresponding estimate in the results for our firm-level panel (-0.1300). Using this aggregate specification, we find the same evidence that higher uncertainty is associated with a weaker impact effect of demand growth on investment.

These results thus indicate that when aggregate and firm-level data are constructed from consistent sources, when the aggregate variables are constructed using exact aggregation, and when the aggregate specification controls for common, unobserved influences on firm-level investment, the results from an aggregate time-series analysis are entirely consistent with the findings of our panel data specification. Unfortunately the aggregate time-series results are found to be very sensitive both to the construction of the aggregate series and to the omission of a good proxy for the common, unobserved shocks. Only when these demanding criteria are met do we obtain an aggregate model that is well specified and identifies the effect of uncertainty on short-run investment dynamics. Since this is generally not feasible without access to the underlying micro data, evidence about uncertainty and investment based on typical aggregate econometric studies should be viewed with considerable caution.

\section{Results from a Monte Carlo Analysis}

In the preceding Sections we have simply assumed that the microeconometric estimates presented in Section 2 were consistent estimates of some underlying parameters of interest. ${ }^{16}$ Differences in the parameter estimates between the panel data and aggregate specifications were attributed to misspecification and/or omitted variables in the aggregate models. In this Section we report the

${ }^{15}$ Augmented Dickey Fuller tests indicate that the time series $k_{t}^{E A}$ and $y_{t}^{E A}$ are both integrated of order one. A cointegration analysis suggests the presence of one cointegrating vector, with coefficients $(1,-1.23)$. The restriction that this cointegrating vector is $(1,-1)$, as imposed in our aggregate specification, is not rejected by the Likelihood Ratio test ( $p$-value $=0.28)$. Further details of these results are available on request.

${ }^{16}$ Bloom, Bond, and Van Reenen (2003) show that an augmented error correction model of this type provides a reasonable empirical representation of the investment data generated by a model of investment under partial irreversibility, when firm-level total investment is an aggregate over multiple types of capital and production plants. 
results of a simple Monte Carlo study that confirms that we should indeed find this sensitivity in the aggregate results if our microeconometric model is correctly specified.

Details of the data generation process and the Monte Carlo results are presented in Appendix IV. In brief, we assume that a model similar to equation (1) describes the evolution of each firm's capital stock, up to a firm-specific effect $\left(\eta_{i}\right)$ and a random shock $\left(\varepsilon_{i t}\right)$. Values for these stochastic terms are drawn from normal distributions, with variances chosen to match those of the residuals in our panel specification. Initial values for each firm's capital stock, and values of sales, cash flow, and measured uncertainty, are obtained from our dataset for U.K. firms, and treated as fixed across replications. The series for the common, unobserved influences $\left(\alpha_{t}\right)$ are again obtained from the estimated coefficients on year-specific intercepts, and also kept fixed across replications. By drawing new values for the shocks $\eta_{i}$ and $\varepsilon_{i t}$ on each replication, and using these to construct series for each firm's investment and capital stocks, we generate 1,000 simulated microeconomic datasets. In each replication of the experiment, aggregate variables are constructed from these simulated firm-level series according to both exact and observed aggregation, and time-series investment equations are estimated using these simulated aggregates, both with and without including the aggregate shock series $\left(\alpha_{t}\right)$ as a control variable.

The key results are presented in Table A.4.2, which confirms that the aggregate investment equation based on exact aggregation and controlling for common, time-varying shocks yields almost unbiased estimates of the parameters that were used to generate the underlying firm-level investment data. This was not the case for either of the aggregate specifications based on observed aggregation, or for the specification based on exact aggregation that did not control for common, unobserved influences. Serious biases were introduced when the appropriate unweighted averages of the microeconomic variables were replaced by the weighted averages imposed by observed aggregation, ${ }^{17}$ and when a good proxy for the the common time-varying shocks was replaced by a simple linear trend. Importantly, the relationship between uncertainty and the impact effect of demand growth on investment, which in this case is known to be present in the simulated firm-level data, was detected only by the aggregate specification based on exact aggregation and controlling for common, time-varying shocks, as reported in Table A.4.2. None of the other aggregate specifications considered in this study produced reliable evidence on the relationship between uncertainty and short-run investment dynamics.

\section{Conclusions}

This study was motivated by important differences between a microeconometric analysis of investment using panel data for U.K. manufacturing firms, and an aggregate time series analysis of investment using data for the U.K. manufacturing sector. These studies presented conflicting evidence about the importance of uncertainty in shaping short-run investment dynamics. Consistent with earlier panel data studies, we found significant evidence that higher uncertainty is associated with a weaker impact effect of demand growth on investment in our microeconometric

\footnotetext{
${ }^{17}$ See equations (7) and (8) above, and the discussion in Section IV.
} 
specification for U.K. firms. However, we could not replicate this evidence using aggregate data for the U.K. manufacturing sector.

Our analysis points to two important reasons why typical aggregate specifications may fail to detect this relationship between uncertainty and investment dynamics. These microeconomic investment equations relate the growth rate of the capital stock to the growth rate of real sales, and to an error correction term that controls for the proportional "gap" between actual and desired levels of the capital stock. None of these terms aggregates conveniently. Moreover in panel data studies it is straightforward and common practice to include year-specific intercepts or "time dummies", which control for all unobserved factors that have a common effect on the investment decisions of firms. These will include interest rates and relative prices (i.e., the user cost of capital), which could in principle be measured, but may also include less tangible influences such as expectations of future growth in aggregate demand, or "business confidence".

By constructing aggregate variables from our firm-level data, we demonstrate that the results of aggregate time series specifications are very sensitive to whether or not the aggregate relationship is implied by exact aggregation of the firm-level investment equations, and to whether or not the aggregate specification controls for unobserved, common influences on firm-level investment decisions. A simple Monte Carlo study confirms that this sensitivity is also found in a setting where we know by construction the process that has generated the underlying firm-level investment data.

This sensitivity to misspecification and omitted variable biases appears to be particularly important for detecting the effect of uncertainty on short-run investment dynamics. Using both real and simulated data, we find that both exact aggregation and controlling for unobserved, common influences are required to detect the relationship between uncertainty and the impact effect of demand growth on investment. Since neither of these requirements is likely to be met in practice, we conclude that evidence about the effects of uncertainty on investment dynamics obtained from typical aggregate econometric studies should be viewed with considerable caution. 
Table 1. Descriptive Statistics - Firm Panel

\begin{tabular}{|c|c|c|c|}
\hline Variable & Mean & Std.Dev. & Median \\
\hline Investment Rate $\left(I_{i t} / K_{i, t-1}\right)$ & 0.123 & 0.113 & 0.102 \\
\hline Real Sales Growth $\left(\Delta y_{i t}\right)$ & 0.024 & 0.147 & 0.026 \\
\hline Std. Dev. of Share Returns $\left(\sigma_{i t}\right)$ & 1.377 & 0.655 & 1.244 \\
\hline Cash Flow $\left(C_{i t} / K_{i, t-1}\right)$ & 0.201 & 0.184 & 0.167 \\
\hline Employment & 18,774 & 34,199 & 5,936 \\
\hline Investment as a Share of Sales $\left(I_{i t} / Y_{i t}\right)$ & 0.049 & 0.058 & 0.037 \\
\hline Observations per firm & 24 & 1.714 & 24 \\
\hline
\end{tabular}

Note: The sample consists of 205 firms and a total of 4,918 observations.

Table 2. Descriptive Statistics - Manufacturing Sector

\begin{tabular}{lcll}
\hline Variable & Mean & Std.Dev. & Median \\
\hline & & & \\
Net Investment Rate $\left(I_{t} / K_{t-1}\right)$ & 0.006 & 0.024 & 0.0058 \\
Real Value Added Growth $\left(\Delta y_{t}\right)$ & 0.008 & 0.041 & 0.0145 \\
Std. Dev. of Share Returns $\left(\sigma_{t}\right)$ & 2.650 & 2.000 & 1.735 \\
Financial Conditions $\left(F I N_{t}\right)$ & 0.041 & 0.019 & 0.0375 \\
\hline
\end{tabular}




\section{Table 3. Firm-Level Investment Equation}

\section{(One-Step GMM Estimates)}

\begin{tabular}{ll}
\hline$I_{i t} / K_{i, t-1}$ & Parameter Estimates \\
\hline$\Delta y_{i t}$ & 0.4291 \\
$\Delta y_{i, t-1}$ & 0.1071 \\
$(k-y)_{i, t-2}$ & 0.0207 \\
& -0.0963 \\
$C_{i, t-1} / K_{i, t-2}$ & 0.0190 \\
$\sigma_{i t} * \Delta y_{i t}$ & 0.0270 \\
& -0.1300 \\
& 0.0538 \\
Sargan (p) & 0.78 \\
LM2 (p) & 0.78 \\
Wald (p) & 0.00 \\
Observations & 4918 \\
Firms & 205 \\
\hline
\end{tabular}

Notes: Asymptotic standard errors robust to heteroskedasticity and serial correlation are reported below the coefficients; estimation by GMM-SYSTEM using DPD98 for GAUSS one-step results; full set of time dummies included; "Sargan" is a Sargan-Hansen test of overidentifying restrictions ( $p$-value reported); "LM(2)" is the test statistic for the absence of 2 nd order serial correlation in the first-differenced residuals, distributed $\mathrm{N}(0,1)$ under the null ( $p$-value reported); "Wald" is a test for the joint significance of time dummies ( $p$-value reported); instruments are $y_{i, t-1}, y_{i, t-2}, y_{i, t-3},(k-y)_{i, t-2}, C_{i, t-1} / K_{i, t-2}$, $C_{i, t-2} / K_{i, t-3}, \sigma_{i, t-1}, \sigma_{i, t-2}$ in the differenced equations, and $\Delta\left(\frac{I_{i, t-1}}{K_{i, t-2}}\right)$ in the levels equations. 
Table 4. Manufacturing-Sector Investment Equation

(OLS Estimates)

\begin{tabular}{ll}
\hline$\left(\frac{I_{t}}{K_{t-1}}\right)^{O N S}$ & Parameter Estimates \\
\hline$\Delta y_{t}^{O N S}$ & 0.0045 \\
$\Delta y_{t-1}^{O N S}$ & 0.0840 \\
$(k-y)_{t-2}^{O N S}$ & 0.1486 \\
$F I N_{t-1}^{O N S}$ & -0.1829 \\
$\sigma_{t}^{O N S} * \Delta y_{t}^{O N S}$ & 0.0326 \\
& -0.1577 \\
& 0.0137 \\
& 0.0307 \\
Serial Correlation (p) & 0.00 \\
Functional Form (p) & 0.00 \\
Normality (p) & 0.08 \\
Heteroskedasticity (p) & 0.90 \\
\hline
\end{tabular}

Notes: Standard errors are reported below the coefficients; estimation by OLS; constant and linear time trend included; "Serial Correlation" is the Lagrange multiplier test of residual first-order serial correlation ( $p$-value reported); "Functional Form" is the Ramsey RESET test using the square of the fitted values ( $p$-value reported); "Normality" is based on a test of skewness and kurtosis of residuals ( $p$-value reported); "Heteroskedasticity" is based on the regression of squared residuals on squared fitted values ( $p$-value reported). 
Table 5. Aggregate Investment Equations - Observed Aggregation

(OLS Estimates)

\begin{tabular}{lcl}
\hline$\left(I_{t} / K_{t-1}\right)^{O A}$ & $(1)$ & $(2)$ \\
\hline$\Delta y_{t}^{O A}$ & -0.0742 & 0.1935 \\
$\Delta y_{t-1}^{O A}$ & 0.2371 & 0.1707 \\
$(k-y)_{t-2}^{O A}$ & -0.0831 & 0.0963 \\
$\left(C_{t-1} / K_{t-2}\right)^{O A}$ & 0.0623 & 0.0464 \\
$\left(\sigma_{t}^{O A} * \Delta y_{t}^{O A}\right)$ & 0.0271 & -0.1161 \\
$t$ & 0.0919 & -0.1445 \\
& 0.0736 & -0.1324 \\
$\alpha_{t}$ & -0.1725 & 0.0323 \\
& 0.0079 & - \\
Serial Correlation (p) & 0.17 & 0.99 \\
Functional Form (p) & 0.09 & 0.40 \\
Normality (p) & 0.14 & 0.69 \\
Heteroskedasticity (p) & 0.29 & 0.55 \\
\hline
\end{tabular}

Notes: Standard errors are reported below the coefficients; estimation by OLS; constant included; "Serial Correlation" is the Lagrange multiplier test of residual first-order serial correlation ( $p$-value reported); "Functional Form" is the Ramsey RESET test using the square of the fitted values ( $p$-value reported); "Normality" is based on a test of skewness and kurtosis of residuals ( $p$-value reported); "Heteroskedasticity" is based on the regression of squared residuals on squared fitted values ( $p$-value reported). 
Table 6. Aggregate Investment Equations - Exact Aggregation

(OLS Estimates)

\begin{tabular}{llll}
\hline$\left(I_{i} / K_{i-1}\right)^{E A}$ & $(1)$ & $(2)$ & $(3)$ \\
\hline$\Delta y_{t}^{E A}$ & -0.5302 & -0.2733 & 0.4308 \\
$\Delta y_{t-1}^{E A}$ & 0.2345 & 0.2095 & 0.0446 \\
$(k-y)_{t-2}^{E A}$ & 0.1398 & 0.0445 & 0.1072 \\
$\left(C_{t-1} / K_{t-2}\right)^{E A}$ & -0.0815 & 0.0735 & 0.0114 \\
$\left(\sigma_{t} * \Delta y_{t}\right)^{E A}$ & 0.0042 & 0.0507 & -0.1041 \\
$t$ & 0.1012 & 0.5321 & 0.0297 \\
& 0.4017 & 0.2379 & 0.0242 \\
$\alpha_{t}$ & 0.1503 & 0.1342 & -0.1249 \\
& - & -0.0054 & - \\
Serial Correlation (p) & 0.14 & 0.0267 \\
Functional Form (p) & 0.06 & 0.0017 & 1.0665 \\
Normality (p) & - & - & 0.0336 \\
Heteroskedasticity (p) & 0.01 & 0.00 & 0.33 \\
\hline
\end{tabular}

Notes: Standard errors are reported below the coefficients; estimation by OLS; constant included; "Serial Correlation" is the Lagrange multiplier test of residual first-order serial correlation ( $p$-value reported); "Functional Form" is the Ramsey RESET test using the square of the fitted values ( $p$-value reported); "Normality" is based on a test of skewness and kurtosis of residuals ( $p$-value reported); "Heteroskedasticity" is based on the regression of squared residuals on squared fitted values ( $p$-value reported). 


\section{Figure 1. Common Time-Varying Shocks}

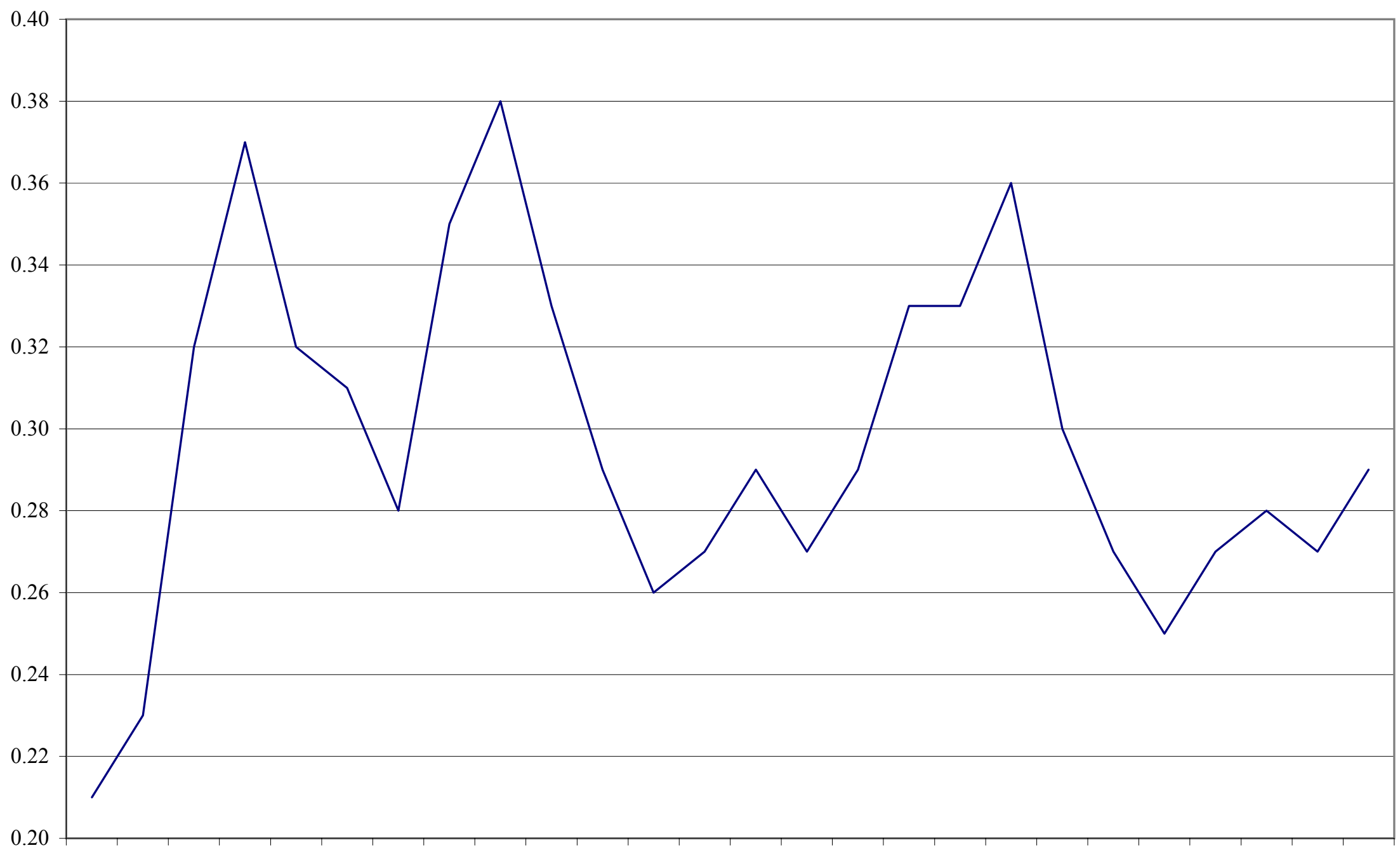

19721973197419751976197719781979198019811982198319841985198619871988198919901991199219931994199519961997 


\section{APPENDiX I: Firm-LeVEl DATA}

\section{A. Investment}

Until 1992, total gross investment in fixed assets (DS435), including fixed assets of newly acquired subsidiaries, net of fixed asset sales (DS423). From 1993 onward, net payments for fixed assets (DS1026) plus fixed assets of newly acquired subsidiaries (DS479). This investment data is obtained from the sources and uses of funds accounts and is not inferred from changes in the balance sheets.

\section{B. Estimation of Capital Stocks}

A capital stock measure for each firm is initially derived from the net book value of the firm's tangible fixed assets and subsequently estimated at current replacement cost using a standard perpetual inventory formula:

$$
P_{t}^{I} K_{t}=(1-\delta) P_{t-1}^{I} K_{t-1}\left(P_{t}^{I} / P_{t-1}^{I}\right)+P_{t}^{I} I_{t}
$$

where:

$K_{t}=$ end-of-period real capital stock

$P_{t}^{I}=$ aggregate price index of investment goods

$I_{t}=$ real gross investment, net of revenues from sales of investment goods

$\delta=$ depreciation rate

The aggregate price index of investment goods used for deflating gross investment, revenues from sales of investment goods and the starting value of the capital stock series are from the ONS. We have assumed that capital depreciates at an annual rate of 8 percent. The benchmark capital stock is assumed to be on average three years old.

\section{Output}

The proxy for a measure of real output is total sales (DS104) deflated by the aggregate GDP deflator.

\section{Cash Flow}

Cash flow is given by net earnings (DS182) plus depreciation deductions (DS136) and is normalized by the previous-period capital stock.

\section{E. Uncertainty}

Our measure of uncertainty is based on a company's daily stock market return from Datastream. Such a measure includes, on a daily basis, the capital gain on the stock, dividend payments, the 
value of rights issues, special dividends and stock dilution. The annual standard deviation of these daily returns is matched precisely to the accounting year.

Table A.1.1. Balance of Panel

\begin{tabular}{c|ccccccc}
\hline Start Year & End Year & 1993 & 1994 & 1995 & 1996 & 1997 & Total \\
\hline & & & & & & & \\
1972 & 6 & 9 & 18 & 8 & 67 & 108 \\
1973 & - & 1 & 2 & 3 & 17 & 23 \\
1974 & & - & - & - & - & 4 & 4 \\
1975 & - & - & - & - & 4 & 4 \\
1976 & - & - & - & - & 66 & 66 \\
Total & 6 & 10 & 20 & 11 & 158 & 205 \\
\hline
\end{tabular}




\section{Appendix II: Aggregate Data}

\section{A. Investment}

Fixed investment by the manufacturing sector in plant, transport vehicles, and nonresidential buildings measured net of depreciation and retirements. Source: ONS.

\section{B. Capital Stock}

Net stock of fixed assets given by plant, transport vehicles, and nonresidential buildings in the manufacturing sector. Source: ONS.

\section{Output}

Real value added by the manufacturing sector. Source: ONS.

\section{Index of Financing Conditions}

This is derived from the quarterly CBI Industrial Trends Survey and represents the annual average percentage of respondents who have pointed to financial considerations (credit finance) as a factor affecting their production in the months ahead when asked "What factors are likely to limit your output over the next four months?" The answers to this question available in the Survey are: Orders; Skilled Labor; Other Labor; Plant Capacity; Credit Finance; Materials; Others.

\section{E. Uncertainty}

This is computed as the annual standard deviation of the daily FTSE share returns index for companies of the nonfinancial sector, the closest proxy for the manufacturing sector available from Datastream. 


\section{Appendix III: The Aggregate Error Correction Term}

The aggregate error correction term in equation (6) is:

$$
\ln \left(\sum_{i=1}^{N} K_{i, t-1}\right)-\ln \left(\sum_{i=1}^{N} Y_{i, t-1}\right)
$$

Under the assumption $\left(\beta_{0}+\beta_{1}\right) /\left(1-\alpha_{1}\right)=1$, equation (3) implies that:

$$
\ln \left(K_{i, t-1}\right) \approx \ln \left(Y_{i, t-1}\right)
$$

on average in the long run. As a result, using the approximation $\ln (1+x) \approx x$ for $x$ small, equation (A3-1) can be approximated as follows:

$$
\ln \left(\frac{\sum_{i=1}^{N} K_{i, t-1}}{\sum_{i=1}^{N} Y_{i, t-1}}\right) \approx\left(\frac{\sum_{i=1}^{N} K_{i, t-1}}{\sum_{i=1}^{N} Y_{i, t-1}}\right)-1
$$

In turn, the right-hand side of equation (A3-3) is:

$$
\left(\frac{\sum_{i=1}^{N} K_{i, t-1}}{\sum_{i=1}^{N} Y_{i, t-1}}\right)-1=\frac{\sum_{i=1}^{N} K_{i, t-1}-\sum_{i=1}^{N} Y_{i, t-1}}{\sum_{i=1}^{N} Y_{i, t-1}}
$$

which can be rewritten in terms of a weighted average:

$$
\frac{\sum_{i=1}^{N} K_{i, t-1}-\sum_{i=1}^{N} Y_{i, t-1}}{\sum_{i=1}^{N} Y_{i, t-1}}=\sum_{i=1}^{N} w_{y, i, t}\left(\frac{K_{i, t-1}-Y_{i, t-1}}{Y_{i, t-1}}\right),
$$

where $w_{y, i, t}=\frac{Y_{i, t-1}}{\sum_{j=1}^{N} Y_{j, t-1}}$.

Finally, noting equation (A3-2), the right-hand side of equation (A3-5) can be approximated as:

$$
\sum_{i=1}^{N} w_{y, i, t}\left(\frac{K_{i, t-1}-Y_{i, t-1}}{Y_{i, t-1}}\right) \approx \sum_{i=1}^{N} w_{y, i, t}\left[\ln \left(K_{i, t-1}\right)-\ln \left(Y_{i, t-1}\right)\right]
$$




\section{Appendix IV: The Monte Carlo Experiment}

\section{A. The Micro Model}

Consistent with the specification used in Section II, we assume that the data generation process for the capital stock is:

$$
\begin{aligned}
\Delta k_{i t}= & \alpha_{t}+\omega_{0} \Delta y_{i t}+\omega_{1} \Delta y_{i, t-1}+\omega_{2}\left(\sigma_{i t} \Delta y_{i t}\right) \\
& +\theta(k-y)_{i, t-2}+\psi\left(\frac{C_{i, t-1}}{K_{i, t-2}}\right)+\eta_{i}+\varepsilon_{i t} .
\end{aligned}
$$

Equation (A.4.1) is analogous to equation (1) in Section II, except that the dependent variable $\Delta k_{i t}$, which avoids the approximation that $\Delta k_{i t} \approx I_{i t} / K_{i, t-1}-\delta$, and simplifies the generation of simulated capital stock data.

To obtain reasonable parameter values, equation (A.4.1) is estimated using the same sample of U.K. manufacturing firms that we used in Section II. Table A.4.1 reports the results for the one-step GMM estimator. 
Table A.4.1. Firm-Level Investment Equation

(One-Step GMM Estimates)

\begin{tabular}{ll}
\hline$\Delta k_{i t}$ & Parameters Estimates \\
\hline$\Delta y_{i t}$ & 0.4073 \\
$\Delta y_{i, t-1}$ & 0.1008 \\
$(k-y)_{i, t-2}$ & 0.0647 \\
$C_{i, t-1} / K_{i, t-2}$ & -0.0628 \\
$\sigma_{i t} * \Delta y_{i t}$ & 0.0556 \\
& 0.0264 \\
& 0.1385 \\
& 0.0517
\end{tabular}

$\begin{array}{ll}\text { Sargan }(p) & 0.63 \\ \text { LM2 (p) } & 0.90 \\ \text { Wald (p) } & 0.00 \\ \text { Observations } & 4918 \\ \text { Firms } & 205\end{array}$

Notes: Asymptotically robust standard errors are reported below the coefficients; estimation by GMM-SYSTEM using DPD98 package one-step results; full set of time-dummies included; "Sargan" is a Sargan-Hansen test of overidentifying restrictions ( $p$-value reported); " $\mathrm{LM}(2)$ ") is the test statistic for the absence of 2 nd order serial correlation in the first-differenced residuals, distributed $\mathrm{N}(0,1)$ under the null ( $p$-value reported); "Wald" is a test for the joint significance of time-dummies ( $p$-value reported); instruments are $y_{i, t-1}, y_{i, t-2}, y_{i, t-3},(k-y)_{i, t-2}, C_{i, t-1} / K_{i, t-2}, C_{i, t-2} / K_{i, t-3}, \sigma_{i, t-1}, \sigma_{i, t-2}$ in the differenced equations and $\Delta\left(\frac{I_{i, t-1}}{K_{i, t-2}}\right)$ in the levels equation.

\section{B. Simulating Capital Accumulation at the Firm Level}

We assume that the following baseline specification describes the capital accumulation path at the firm level:

$$
\begin{aligned}
k_{i t}= & \alpha_{t}+\alpha_{1} k_{i, t-1}+\alpha_{2} k_{i, t-2}+\beta_{0} y_{i t}+\beta_{1} y_{i, t-1}+\beta_{2} y_{i, t-2} \\
& +\gamma_{0} \frac{C_{i, t-1}}{K_{i, t-2}}+\gamma_{1} \sigma_{i t} \Delta y_{i t}+\eta_{i}+\varepsilon_{i t}
\end{aligned}
$$

with $k_{i t}$ being the log of the $i t h$-firm's capital stock at time $t$ and $\gamma_{1}$ representing the effect of uncertainty on the response of investment to current real sales growth.

To generate a firm's capital stock series using equation (A.4.2), we need to assign values to the set of parameters $\left(\alpha_{1}, \alpha_{2}, \beta_{0}, \beta_{1}, \beta_{2}, \gamma_{0}, \gamma_{1}\right)$, to the aggregate shock series $\left(\alpha_{t}\right)$ and, finally, to the random shocks $\eta_{i}$ and $\varepsilon_{i t}$. 
In the following subsections, we discuss how to proceed.

\section{Deriving the Parameters for the Capital Accumulation Equation}

To obtain the values for $\left(\alpha_{1}, \alpha_{2}, \beta_{0}, \beta_{1}, \beta_{2}, \gamma_{0}, \gamma_{1}\right)$, it is helpful to reparameterize equation (A.4.2) and consider its error correction formulation:

$$
\begin{aligned}
\Delta k_{i t}= & \alpha_{t}+\left(\alpha_{1}-1\right) \Delta k_{i, t-1}+\beta_{0} \Delta y_{i t}+\left(\beta_{0}+\beta_{1}\right) \Delta y_{i, t-1} \\
& +\gamma_{0} \frac{C_{i, t-1}}{K_{i, t-2}}+\gamma_{1} \sigma_{i t} \Delta y_{i t}-\left(1-\alpha_{1}-\alpha_{2}\right)(k-y)_{i, t-2} \\
& +\left[\beta_{0}+\beta_{1}+\beta_{2}-\left(1-\alpha_{1}-\alpha_{2}\right)\right] y_{i, t-2}+\eta_{i}+\varepsilon_{i t} .
\end{aligned}
$$

By comparing the coefficients in equation (A.4.3) and equation (A.4.2), we can recover estimates for the parameters we need based on the results in Table A.4.1. Notice that the long-run proportionality restriction $\left[\beta_{0}+\beta_{1}+\beta_{2} /\left(1-\alpha_{1}-\alpha_{2}\right)\right]=1$ is imposed, consistent with the empirical evidence presented previously.

\section{Generating Random Shocks}

Before generating the capital stock series, we need to assign values to the firm-specific effect $\left(\eta_{i}\right)$ and to the idiosyncratic shocks $\left(\varepsilon_{i t}\right)$ in (A.4.2). We generate these random shocks from mean-zero normal distributions with the same variances as estimated for our firm-level data. In order to derive suitable estimates for $\operatorname{Var}\left(\varepsilon_{i t}\right)$, we estimate the following equation in first differences by OLS on the same firm-level dataset:

$$
\Delta^{2} k_{i t}-\widehat{\beta}^{\prime} \Delta X_{i t}=\Delta \alpha_{t}+\Delta \varepsilon_{i t}
$$

Here, $X_{i t}=\left(\Delta y_{i t}, \Delta y_{i, t-1}, \frac{C_{i, t-1}}{K_{i, t-2}}, \sigma_{i t} \Delta y_{i t},(k-y)_{i, t-2}\right)^{\prime}$ is the vector of explanatory variables used in Table A.4.1, $\Delta^{2} k_{i t}=\Delta k_{i t}-\Delta k_{i, t-1}$ is the dependent variable in equation (A.4.3) and Table A.4.1 in first differences, and $\widehat{\beta}$ is the vector of parameter estimates reported in Table A.4.1. Regressing the transformed dependent variable on a set of year dummies gives residuals that are estimates of $\Delta \varepsilon_{i t}$, from which $\operatorname{Var}\left(\varepsilon_{i t}\right)$ can be estimated, noting that $\operatorname{Var}\left(\Delta \varepsilon_{i t}\right)=2 \operatorname{Var}\left(\varepsilon_{i t}\right)$ under the assumption that the $\varepsilon_{i t}$ are serially uncorrelated shocks. 
In addition, we estimate the following specification in levels:

$$
\Delta k_{i t}-\widehat{\beta}^{\prime} X_{i t}=\alpha_{t}+\left(\eta_{i}+\varepsilon_{i t}\right)
$$

from which we can obtain an estimate for $\operatorname{Var}\left(\eta_{i}\right)$ under the assumption that

$$
\operatorname{Var}\left(\eta_{i}+\varepsilon_{i t}\right)=\operatorname{Var}\left(\eta_{i}\right)+\operatorname{Var}\left(\varepsilon_{i t}\right)
$$

The estimated values for $\operatorname{Var}\left(\eta_{i}\right)$ and $\operatorname{Var}\left(\varepsilon_{i t}\right)$ are respectively equal to 0.0034 and to 0.0056 . Therefore, to simulate random shocks to the capital accumulation path, shocks are randomly drawn from $\eta_{i} \sim N(0,0.0034)$ and $\varepsilon_{i t} \sim N(0,0.0056)$.

\section{E. Simulating Capital Stock Data}

At this stage, we have gathered all the elements needed for using equation (A.4.2) in order to simulate capital stock data at the firm level. We simulate a capital stock series for each firm from $t=3$ onward, using the firm's actual data on real sales, cash flow, and measured uncertainty, initializing the series using the actual capital stock data for $k_{i, 1}$ and $k_{i, 2}$. Applying this procedure for each firm in the sample generates one micro panel dataset. We draw new values for the firm-specific effects $\left(\eta_{i}\right)$ and the idiosyncratic shocks $\left(\varepsilon_{i t}\right)$ and repeat this process 1,000 times to generate the 1,000 samples used in our Monte Carlo analysis. Notice that the starting values and the explanatory variables (real sales, cash flow, measured uncertainty and the aggregate shock series) are thus kept fixed across replications.

\section{F. Results}

On each replication of the experiment, the simulated firm-level data was aggregated and used to estimate the four aggregate specifications considered in Sections VI and VII. Table A.4.2 reports the mean and standard deviation of the parameter estimates (across the 1,000 replications) for the aggregate specification based on exact aggregation and including the series $\alpha_{t}$ to control for common, time-varying shocks. The mean of these parameter estimates is very close to the parameters that were used to contruct the underlying firm-level data (i.e., the micro parameter estimates reported in Table A.4.1). The means of the standard errors for each of these estimated 
parameters are also close to the empirical standard deviation of the corresponding parameter estimates, as required for inference based on these standard errors to be reliable.

Table A.4.2. Aggregate Investment Equation under Exact Aggregation (Averages from OLS Estimates with Common Time-Varying Shocks)

\begin{tabular}{cccc}
\hline \multirow{2}{*}{ Variables } & \multicolumn{3}{c}{ Parameter Estimates } \\
\cline { 2 - 4 } & \multicolumn{2}{c}{ Coefficients } & Std. Errors \\
\cline { 2 - 4 } & Mean & Std. Dev. & Mean \\
\hline & & & \\
$\Delta y_{i t}$ & 0.4078 & 0.1165 & 0.1041 \\
$\Delta y_{i, t-1}$ & 0.0649 & 0.0298 & 0.0285 \\
$(k-y)_{i, t-2}$ & -0.0628 & 0.0152 & 0.0153 \\
$C_{i, t-1} / K_{i, t-2}$ & 0.0549 & 0.0288 & 0.0285 \\
$\sigma_{i t} * \Delta y_{i t}$ & -0.1392 & 0.0710 & 0.0641 \\
$\alpha_{t}$ & 0.9999 & 0.0489 & 0.0415 \\
\hline
\end{tabular}




\section{REFERENCES}

Abel, Andrew B., and Janine C. Eberly, 1999, "The Effects of Irreversibility and Uncertainty on Capital Accumulation,” Journal of Monetary Economics, Vol. 44, 339-377.

Arellano, Manuel, and Stephen Bond, 1991, "Some Tests of Specification for Panel Data: Monte Carlo Evidence and an Application to Employment Equations", Review of Economic Studies, Vol. 58, 277-297.

Arellano, Manuel, and Stephen Bond, 1998, "Dynamic Panel Data Estimation Using DPD: a Guide for Users", Institute for Fiscal Studies Working Paper no. 88/15.

Bank of England (2002), "Explaining Trends in U.K. Business Investment”, Bank of England Quarterly Bulletin, Spring, 33-41.

Bloom, Nicholas, 2000, "The Real Options Effect of Uncertainty on Investment and Labour Demand", Institute for Fiscal Studies Working Paper no. 00/15.

_ Stephen R. Bond, and John Van Reenen, 2003, "Uncertainty and Company Investment Dynamics: Empirical Evidence for U.K. Firms," Centre for Economic Policy Research Discussion Paper no. 4025.

Blundell, Richard, and Stephen R. Bond, 1998, "Initial Conditions and Moment Restrictions in Dynamic Panel Data Models," Journal of Econometrics, Vol. 87, 115-143.

Bond, Stephen R., Julie A. Elston, Jacques Mairesse, and Benoit Mulkay, 2003, "Financial Factors and Company Investment in Belgium, France, Germany and the U.K.," Review of Economics and Statistics, Vol. 85, 153-165.

Bond, Stephen R., Dietmar Harhoff, and John Van Reenen, 1999, "Investment, R\&D and Financing Constraints in Britain and Germany," Institute for Fiscal Studies Working Paper no. $99 / 5$.

Bond, Stephen R., and Domenico Lombardi, 2004, “To Buy or Not to Buy? Uncertainty, Irreversibility, and Heterogeneous Investment Dynamics in Italian Company Data”, International Monetary Fund Working Paper no. 04/104.

Caballero, Ricardo, 1999, “Aggregate Investment,” in John B. Taylor and Michael Woodford (eds.), Handbook of Macroeconomics, Vol. 1, North-Holland, Amsterdam.

Goldberg, Linda S., 1993, "Exchange Rates and Investment in United States Industry", The Review of Economics and Statistics, Vol. 75, 575-588.

Guiso, Luigi, and Giuseppe Parigi, 1999, “Investment and Demand Uncertainty," Quarterly Journal of Economics, Vol. 114, 185-227.

Hsiao, Cheng, 1986, “Analysis of Panel Data”, Econometric Society Monographs, Cambridge University Press.

Huizinga, John, 1993, "Inflation Uncertainty, Relative Price Uncertainty, and Investment in US Manufacturing”, Journal of Money, Credit, and Banking, Vol. 25, 521-554. 
Koeva, Petya, 2003, “U.K. Investment: Is There a Puzzle?”, International Monetary Fund unpublished.

Leahy, John and Tony M. Whited, 1998, "The Effects of Uncertainty on Investment: Some Stylized Facts", Journal of Money, Credit, and Banking, Vol. 28, 64-83.

Windmeijer, Frank, 2000, “A Finite Sample Correction for the Variance of Linear Two-Step GMM Estimators,” Institute for Fiscal Studies Working Paper no. 00/19. 